British Journal of Environment \& Climate Change 6(3): 170-178, 2016, Article no.BJECC.2016.017

ISSN: 2231-4784

SCIENCEDOMAIN international

www.sciencedomain.org

\title{
Customer Attitudes to Water Use and Its Conservation
}

\author{
James O. Jenkins ${ }^{{ }^{*}}$, Alexis Pericli ${ }^{1}$ and Lisa Palframan ${ }^{1}$ \\ ${ }^{1}$ Department of Human and Environmental Sciences, University of Hertfordshire, AL10 9AB, England.
}

Authors' contributions

This work was carried out in collaboration of all authors. Author JOJ designed the study, analyzing the data in conjunction with author AP. Authors JOJ and LP collected the data. Author JOJ prepared the manuscript. Finally, all authors read and approved the final manuscript.

Article Information

DOI: 10.9734/BJECC/2016/18182

Original Research Article

Received $8^{\text {th }}$ April 2015

Accepted $28^{\text {th }}$ April 2016

Published 25 ${ }^{\text {th }}$ August 2016

\section{ABSTRACT}

Aims: Understanding how customers engage with and view their water usage is crucial to the design of more effective water demand management policies and programmes. This paper presents the findings of a small-scale research project that sought to explore customer attitudes to the use of water and its conservation, particularly in the context of seasonal tariffs used during the summer peak usage months (May to August).

Study Design: The study adopted a qualitative approach, implemented through a series of faceto-face semi-structured interviews.

Place and Duration of Study: The study was conducted with domestic water users in Bishops Stortford, East Hertfordshire (UK). The research was carried out by staff from the School of Life and Medical Sciences at the University Hertfordshire. The study was conducted over a period of 6 weeks.

Methodology: A series of 20 face-to-face semi-structured interviews were carried out with a predefined sample population. The selected customers were split into two equal sized groups depending on their relative water usage to reflect either an increase or a decrease in water usage [as a consequence of Affinity Water's seasonal tariff trial].

Results and Discussion: The study highlights study participants as being disengaged from their water usage and the associated efforts to reduce their usage, so simply increasing water prices at seasonal peak usage times was not, on this occasion, an effective method to adopt to reduce domestic water usage. However, by subsequently exploring customer attitudes towards a selected range of alternative water conservation measures, such as the subsidisation of water efficient appliances, and rebates for reduced water usage, it is established that alternative water conservation measures may have the potential to more effectively encourage a reduction in water usage. However, as the findings of this study also serve to highlight, the issue of 'institutional trust' 
emerges as a key issue to consider when seeking reductions in water usage by increasing its unit cost, with accusation of profiteering looming large.

Conclusion: It is suggested that a richer mix of policy responses demand management will be needed to convince domestic water users of the need to reduce their water usage.

Keywords: Domestic water consumption; seasonal tariff; water conservation; customer attitudes.

\section{INTRODUCTION}

As world demand for water increases and shows no sign of decline [1-2], understanding how customers engage with and view their water usage is crucial to more effective water demand management policies and programmes [3-5]. Metering is envisaged as playing a central role in better managing water resources and reducing demand [4,6-8]. In the context of the United Kingdom (UK), whilst it has been found that the metering of domestic users can reduce initial [short-term] water consumption by about 10 per cent [9], little is known about how seasonal tariffs affect customer demand for and attitudes to water usage [over the medium to long term]. From a theoretical standpoint, seasonal tariffs are envisaged as being able to affect a reduction in water demand during the traditional summer peak demand period, yet research studies currently underway in the United Kingdom, in particular work being carried out by Affinity Water (UK) (a privately owned water supply only company based in the South East of England), and from which this work stems, appears to cast doubt on this assumption. Affinity Water is a privately owned When research studies into human behaviour are explored, it is notable that simple cost signals, in the form of seasonal price differentials, may not be enough to affect a change in behaviour. Indeed, it is important to state that human behaviour itself is shaped by a wide variety of 'other' and 'external' factors alongside concerns over cost. In particular, it has been found that age, gender, income, education, infrastructure/available services, and political affiliation can all affect behaviour, particularly with regard to water usage [5,10-17]. It is also worth noting that wider dimensions of attitudinal and behavioural variability, including notions of emotional involvement, participation, institutional trust, and an attitude-behaviour gap, also serve to shape human perceptions, attitudes, and behaviour in relation to environmental services and conservation measures [13,18-21].

\subsection{Background to This Study}

In an attempt to reduce demand for water during the seasonal peak demand period of the summer months (May to August), Affinity Water (UK) implemented a seasonal tariff metering trial in the area of Bishops Stortford, Hertfordshire, United Kingdom. The main purpose of the study was to assess the potential relationship between a change in water price/cost and relative demand for water during the peak demand period of the summer months. However, contrary to the expected impact of seasonal tariffs, the usage data collected by Affinity Water for the period (2009-2011) appeared to demonstrate average summer monthly consumption as increasing by approximately $3 \%$ in comparison to other metered customers in the local area, who were not subject to a seasonal tariff. A key constraint of the seasonal tariff trial was that it was designed and implemented in the context of a 'cost-neutral' framework so as to comply with the regulatory conditions placed upon them by the water industry's economic regulator Ofwat. This resulted in the application of a seasonal tariff trial that involved prices increasing during the peak summer months but then being decreased during lower demand months so as to achieve a level of cost neutrality for consumers whose consumption remained the same throughout the year as a whole. The implications of this regulatory constraint on both the Affinity water trial, and in turn this study, it subsequently explored in the conclusions sections of this paper.

As a consequence of the above findings, Affinity Water commissioned research exploring customer attitudes to seasonal tariffs, in an attempt to identify possible influencing factors that may underlie the observed increase in water consumption. Therefore, this research, sought to explore customer attitudes to the seasonal tariff trial in an attempt to reveal why there had been an observed increase in water consumption. However, the study also sought to explore customer awareness of, and attitudes toward, water use and its monitoring. The justification for this focus was that if water users are unaware of the amount of water they are using and how they can monitor it, pricing controls such as the seasonal tariff may well be meaningless. Attitudes toward current and alternative pricing approaches, as well as alternative conservation 
approaches, were also the focus of a number of questions. This part of the study was undertaken to identify how much support existed for differential pricing and other conservation methods, including subsidies and rebates, with the overall aim being to identify alternative policy mechanisms and practical approaches to water conservation that may encourage a reduction in water consumption.

\section{METHODOLOGY}

From a broad perspective, the research undertaken for this study adopted a qualitative approach, implemented through a series of faceto-face semi-structured interviews with a predefined sample population located within the area of Bishops Stortford (UK). Due to the exploratory nature of the research, a semistructured interview approach was preferred in order to provide both a basic structure/format as well as a degree of flexibility to facilitate the acquisition of underlying attitudes and detailed expansion with regard to certain topics, particularly where 'yes' or 'no' answers would be given. Qualitative discussion it was then felt could be used to examine the responses in more detail thus allowing for the quantitative data set obtained for certain answers to be explored in more detail [22]. Of course, it is acknowledged that the small data set for this study enabled this approach, and that for a larger data set such an approach may have been feasible due to time and staff constraints.

A total of twenty customer households were selected for participation in the study. The selected customers were split into two equal sized groups depending on their relative water usage to reflect an increase or a decrease in water usage [as a consequence of Affinity Water's seasonal tariff trial]. It is not known by how much users in each group demonstrated an increase or decrease in water usage, as this information was not provided to the authors of this paper. It is acknowledged that further information in this regard would help to enhance to robustness of the study's findings. Although customers were selected randomly for each user group, care was taken to ensure participants were located throughout the entire study area. In turn, this helped to ensure that the sample of customers selected for interview were as representative as feasibly possible within the confines of the available data set and given geographical area.
A case study approach was utilised in order to identify and better understand customer responses to the seasonal tariff trial, and which in the case of this study resulted in the data collection being restricted to a pre-determined number of semi-structured interviews being undertaken. This focus, as with case studies in general, offers a more detailed level of information that can be used to highlight how the convergence of different variables in a given situation and setting can ultimately produce a particular outcome [22-23]. It is acknowledged, that the general contextualisation of the results obtained from small sample research can be potentially limited, however this does not diminish the significance of the study method. In fact, the purpose of the case study approach is to analyse a particular case through a focused lens in order to gain a deeper level of understanding, rather than a broader but more superficial overview of trends or patterns. However, in achieving this depth and richness of information, the scope of a study must be narrowed given the limited resources that are available for a single study (Patton, 2002). Furthermore, in the context of this research, it was necessary for the case study and sample size to be set within the margins of the exclusive water usage data set that was provided by Affinity Water.

The data collection and analysis process was implemented through three key phases, which involved; making initial contact with the respondents; carrying out the interviews; and subsequently analysing the obtained data. Firstly, during the initial contact stage, an introductory letter was sent to potential respondents in order to gain the cooperation, confidence, and trust of interviewees. This letter provided background information on the study, whilst also explaining the reason for the research study and interview. The introductory letter served to incentivise potential participants by making it clear that they would be entitled to a $£ 50$ payment upon completion of the interview. Secondly, once initial contact with all respondents had been achieved, the interviews could be scheduled and completed accordingly. The twenty face-to-face interviews were carried out during July and August 2011. An interview schedule was designed to explore a range of topics relating to water conservation and the seasonal tariff, including; knowledge, awareness, behavioural intention, contextual variability, perceived responsibility, involvement, and communication. 
It is important to note that when investigating public attitudes to water that research has emphasised the importance of sociodemographic variables in explaining observed attitudes and behaviour. However, such considerations did not play a part in this study due to the relatively small sample making it impossible to reliably consider the impact of such background conditions. Thus, whilst care should be exercised with regard to the wider applicability of the findings of this study, they are subsequently discussed in the context of the related research base on attitudes to water consumption. This approach is both widely practiced and valid [23,24-26]. Indeed, the work of Randolph and Troy [5] was consulted and subsequently drawn upon in shaping this type of study. In particular, in relation to their exploration of attitudes to water usage, pricing, and water saving in the home.

\section{RESULTS AND DISCUSSION}

The study findings have been split into four subsections. The first section focuses on exploring respondent engagement with the seasonal tariff trial and its impact on behaviour. The second section focuses on discussing respondent awareness of water use, charges, billing frequency, and the impact of metering on behaviour. The third section focuses on exploring respondent attitudes to water charges and conservation measures. The final section focuses on discussing respondent attitudes to alternative approaches to water conservation.

\subsection{Customer Engagement}

When participants were asked whether or not water usage inside their home had changed as a result of the seasonal tariff trial, $85 \%$ of respondents stated that it had not changed since the introduction of the seasonal tariff, with no one usage group appearing more aware of any change. This finding is in contrast to the usage data for the two groups created for this study, where $50 \%$ of respondents were known to have exhibited a decrease and $50 \%$ an increase in water usage. Subsequent interviewee comments revealed a range of issues which potentially explain this low level of awareness. In particular, respondents felt their household usage had not changed because not all members of the household were aware of the trial; they felt they were already careful with water and so had not instigated any changes as a result of the trial; water was not viewed as a seasonal issue; and a change in behaviour was not felt to be necessary because the costs involved were not a concern. $20 \%$ of all respondents claimed they had either forgotten about the trial or were not aware that they were participating in a seasonal tariff trial.

The responses of those interviewed serve to highlight that respondents had a low level of awareness of how their usage may or may not have changed as a result of the seasonal tariff trial. Indeed, it is notable that $70 \%$ of those in the decrease usage group said they did not know if their water use had changed. This data, in combination with the finding that $85 \%$ of participants felt that their usage had not changed, raises the possibility that any observed decrease in water usage when the seasonal tariff trial was in operation was mainly attributable to chance [or other factors]. The following interview comment, from respondents demonstrating a decrease in water usage, is illustrative and in turn supportive of this view:

"It's probably stayed the same [...] because we're generally water conscious and we've made no lifestyle changes since being in the seasonal tariff. We all shower in the morning, people then like to have a bath as well in the evening. We've had a water butt since before the seasonal tariff started. I don't see that the seasonal tariff has had any impact on our habits". (Decrease)

With regard to the increased usage group, it is notable that while some displayed awareness that their usage had increased, others had little to no understanding of whether their usage had increased or decreased as result of the seasonal tariff trial, as exemplified by the following comment:

"It's funny, if I had to guess l'd say decreased but I know from looking back over my recent bills that actually we've increased our use. I'm not really sure why that is. I do water the garden and wash my cars every week but other than that I feel we've cut down on water use more generally". (Increase)

When respondents were asked if the seasonal tariff trial had prompted them to fit any water saving devices, $90 \%$ of respondents said no. In this respect, it is notable that both usage groups reported in equal measure the non-fitting of water saving devices as a result of the trial. Furthermore, when respondents were asked what actions they had taken to reduce water usage during the last year, particularly when the 
seasonal tariff was in place, $60 \%$ of respondents reported that they had done nothing. However, it is notable that $40 \%$ of respondents did claim that they had taken action to reduce their water usage, with the most frequent action being the 'reuse of water for garden activities' (30\%). It is striking that the usage group claiming to have taken the most actions is the increase group $(50 \%)$, with the decrease group demonstrating the greatest inaction (70\%). However, this result could in part be due to the fact that many in the decrease group were potentially already active in taking action to reduce their water usage prior to the introduction of the seasonal tariff.

When the issue of how much further respondents could go in saving water was explored, only a limited number of respondents suggested that they could do much more to save water and change their behaviour. In particular, just 5\% thought they could do a lot more, $20 \%$ thought they could do some more, with $55 \%$ claiming they could only do a little more and $20 \%$ saying they could do nothing more. However, with respect to the usage groups, it is notable that respondents in the increase group offered a more positive response to being able to conserve water. This finding is similar to the research findings of Randolph and Troy [5], who found that water customers in Sydney, Australia, also viewed themselves as being unable to save much more water.

When interviewees were asked if more regular billing and information on the seasonal tariff trial would have encouraged them to think more about how much water they were using, respondents agreed that it would serve to engage them more and that they may then respond in a more positive manner. In this respect, research on the impact of communication on customer engagement with environmental initiatives has found that a lack of communication can serve to affect a decline in emotional involvement, awareness, perceived control, and personal responsibility [19,27]. Indeed some interviewees did comment that being able to submit readings online for their gas and electricity usage, and being able to compare usage between month and years, did serve to engage them more and in turn encourage them to reflect on how they could alter their behaviour.

\subsection{Customer Awareness}

Approximately $65 \%$ of respondents said they knew how much they paid for their domestic water services, with the remainder not knowing. However, it is notable that while those individuals participating in the seasonal tariff trial were billed every six months, $40 \%$ of respondents said they either did not know how often they received a bill or that they thought they received a bill quarterly, which is not the case. Indeed, if one was to assume that those individuals demonstrating a decrease in consumption are more aware of what they pay and how often they are billed, the results of this study demonstrate the opposite. Therefore, in combination with the finding that those in the decrease group were not aware of whether or not their usage had changed as a result of the trial, it is questionable whether the decrease in water usage was the result of deliberate actions, as noted previously. So, in reality what has been observed with regard to water usage may have been more due to chance than a series of deliberate actions, as those in the decrease group appear to be no more aware than those in the increase group.

When respondents were asked how much water they use, only $5 \%$ of respondents said they knew. The following interviewee comments serve to typify and further exemplify responses received:

"Absolutely no idea [...] a cubic metre of water means nothing to me [...] it really is hard to understand how much water you are using and what that actually means, entails etc...". (Increase)

"No, not a clue". (Decrease)

This low level of awareness is not unusual, and is supported Randolph and Troy (2008) who found that only $19 \%$ of water customers in Sydney, Australia, were aware of how much water they used. Despite the aforementioned low level of awareness, $85 \%$ of respondents thought they were average or below average users of water compared with similar users in their area. In particular, $50 \%$ of respondents thought they used average amounts of water, while 35\% thought they were below average users. However, it is unlikely that such a large percentage would be low water users in reality [see 5]. Again, when the results obtained for this study are broken down, the results obtained do not show any one usage group as being more aware of their water use, which again appears to suggest that the decrease in water usage exhibited by those in the decrease group is down to chance and does not appear to be the result of 
any deliberate change in behaviour driven by the introduction of the seasonal tariff.

When respondents were asked how often they check their water meter, as a way of gauging how much water they use, $95 \%$ of respondents claimed they had never checked their water meter, with there being no significant difference between usage groups in this respect. When respondents were subsequently asked if receiving a metered bill made them reflect on how much water they used and whether they then took action to reduce their usage, $60 \%$ of respondents suggested that receiving a metered water bill did not make them reflect and take action. When it was explored with respondents why they 'never' checked their meter a series of reasons emerged. In particular, issues around the location and accessibility of the meter; not knowing where the meter was; not having access to the meter; and the cost of water supplied not being a major source of household expenditure to warrant further checking.

Although $40 \%$ of respondents did feel that receiving a metered bill did, if albeit temporarily, make them reflect on their water usage, the majority of respondents felt that receiving a metered bill did not affect their behaviour. The reasons for this were that their water usage habits were necessary, water usage costs were considered to be relatively low and, they were already being economical so being metered did not affect them. Some felt they lacked knowledge as to how much water certain appliances used which made considering taking action a pointless exercise. Again no particular differences in the reasons offered were detected between the two usage groups.

\subsection{Water Charges and Conservation}

When the perceived fairness of current water charges and their ability to encourage water conservation were explored, $60 \%$ of respondents thought that current water prices were fair, with $10 \%$ feeling that they were not fair. Both usage groups were equal in their responses to this question. However, it is notable that when asked if current overall water charges encouraged the conservation of water, $60 \%$ of total respondents thought that current prices did not encourage conservation, with $30 \%$ thinking that current prices did encourage conservation. However, it is notable that twice as many in the decrease group did feel that current water prices did encourage water conservation, with $70 \%$ of those in increase group, as compared to $50 \%$ in the decrease group, feeling that they did not encourage conservation. When it was subsequently explored with respondents whether or not extra charges should be made for higher than average water use, $60 \%$ of respondents thought that extra charges should apply for higher than average water use, with $20 \%$ more respondents in the increase group feeling this to be a reasonable course of action.

Despite widespread support for differential pricing to encourage water conservation, and a majority of respondents feeling that current water prices did not encourage conservation, it is notable, and somewhat paradoxical, that $80 \%$ of respondents stated that water prices should not be increased in order to encourage people to use less water / water conservation, with $75 \%$ of respondents not agreeing with the idea of general price increases to fund improvements in conservation policies and practices with regard to water use. Thus the aforementioned responses appear to indicate that people feel they should not have to pay more for their everyday use of water but are tolerant and accepting of the idea that higher than average users should pay more, which they may or may not consider themselves to be. As to why respondents were against water prices being increased to encourage people to use less water, it seems that respondents view water as an essential resource people cannot do without and subsequent usage is therefore seen as somehow fixed and unalterable:

"No, because it would penalise everyday usage and that would not be fair [...] I can't do anything about my usage [...] (water) is not something that you think about when you use it". (Decrease)

With regard to being against increased prices to pay for improved conservation policies and practices aimed at conserving water, issues of trust and concerns over the use of the resultant funds were expressed by many of those interviewed:
"Absolutely not, particularly when water companies are making such high profits". (Decrease)
"If that is where the money goes, and I doubt it would [...] I think it is something to consider so long as you could clearly demonstrate that is where the money went and not on reducing leakage for instance". (Increase)


The above discussion and associated respondent comments highlight issues relating to trust and respondent understanding. Therefore, future policies and practices, particularly with customer cost implications, do need to take into account how a water provider can more effectively cognitively align itself with its customers. Such cognitive alignment is crucial to increasing the effectiveness of attempts to alter customer behaviour. It is notable that research by Blake [28] and Jorgensen et al. [29] serves to highlight that an apparent lack of trust between customer and company can have a detrimental effect on conservation initiatives with mutual understanding of each other's concerns being key to effective conservation initiatives.

\subsection{Alternative Approaches to Water Conservation}

During the course of the study, consideration was given to identifying and subsequently exploring respondent attitudes toward alternative approaches aimed at encouraging a reduction in water use. When respondents were asked if they would allow someone to fit a 'free' water saving device for them in their home, $70 \%$ of respondents were found to be in favour of such a service, with both usage groups being equally positive in this respect. Therefore, this finding suggests that a reduction in water use is possible if water providers were to engage in a programme of fitting water saving devices which may help to overcome customer cost concerns and apathy in fitting such devices themselves.

When customers were asked if they took into account the water consumption of household appliances when making a related purchasing decision, $60 \%$ of those interviewed said that they did consider this issue, with $75 \%$ of interviewees saying that the subsidisation of more water efficient household appliances would encourage them to subsequently purchase such appliances.

When customers were asked if a rebate on their water bill would incentivise them to try to reduce their water usage, $70 \%$ of respondents claimed that they would be 'more likely' to try and reduce their water consumption if they were offered a monetary rebate on their water bill. Such a move, rather than simply charging customers more at a certain time of year, might help to more effectively encourage customers to reduce their water usage via the fitting of water saving devices and/or the adopting of water saving behaviours around the home. It is of note that this finding mirrors wider research suggesting that rebates can act as a 'facilitating factor' that encourages the fitting of water saving devices and/or the adoption of water saving behaviour because it helps to overcome barriers to change attributable to the relatively inexpensive cost of water not encouraging the adoption of efficiency devices and/or a change in behaviour [see $18,21]$.

\section{CONCLUSION}

In similarity with other work that has focused on exploring public attitudes toward water use, the findings of this research study suggest that whilst respondents are aware of the need for water conservation, with many expressing good intentions, respondents appear to be disengaged from their water usage and attempts to reduce their usage via the introduction of a seasonal tariff. The findings of this study strongly suggest that simply increasing water prices at seasonal peak usage times, particularly in the context of cost-neutral framework, is unlikely to be an effective method of managing domestic water demand in the short to medium term. In particular, it was found that the vast majority of respondents, in both usage groups, had not altered their behaviour, or fitted water saving devices, since the start of the seasonal tariff trial, nor did they plan on changing their behaviour. Indeed, the study reveals consumers in the wider trial as being potentially unconcerned and unaware of how of much water they are using, with the majority of respondents being found to never check their water meter or as being concerned about what they are paying for water services. Indeed, the results of the study serve to suggest that any decrease in water usage observed is probably more due to chance rather than a series of deliberate actions by consumers.

This study has also revealed that customers are unwilling to pay more for their water to improve its conservation. In fact, this study suggests that customers in general think that their water consumption is not a problem and that they should not have to pay for a solution. This is not to say, as Randolph and Troy [5: 453] have observed, that customers 'who use substantial amounts of water should not be charged more', it is more that customers feel they should not have to because they are not the problem. This finding, in combination with customers being found to be distrusting of what water companies would do with any increased revenues associated with conservation efforts, does raise the need for more effective knowledge transfer 
partnerships to be developed between not only the company and the customer, but also the regulator.

Finally, the findings of this study, in conjunction with previous research, are illustrative of the need for respondents to be targeted with a diverse range of policies and programmes at any one time, particularly if a sustained and more effective decrease in water usage is to be achieved. This study has revealed substantial potential demand for a number of different water usage reduction schemes, for example, the free fitting of water saving devices and the subsidisation of water efficient household appliances. If embraced, such measures have the potential not only to deliver immediate reductions in water usage but provide long term solutions to reducing it, as they have in other countries. Also, the study has revealed customer support for a 'bill rebate' to encourage a reduction in water usage. Therefore, in combination with the finding that customers may be somewhat distrusting of the company rationale for embracing certain water conservation techniques, it is apparent that greater attention needs to be paid, by both government and water provider alike, to developing sustained and targeted education campaigns focused on building trust between all stakeholders involved in the delivery of water. A simple one-policy-fits-all approach, such as seasonal tariffs, is unlikely to achieve permanent long-term reductions in water usage, particularly if poor customer knowledge and issues of trust are allowed to fester or worsen. Such reflection and appropriate action is argued as being crucial to facilitating a reduction in water usage, particularly when approaches connected with metering have to adopt a 'cost-neutral' framework, as is the case for England and Wales.

\section{ACKNOWLEDGEMENTS}

Significant thanks are expressed to Affinity Water in the United Kingdom. In particular, the cooperation and support of Mr Mike Pocock and Mr Alex Back are acknowledged. The authors are keen to highlight that whilst the research detailed in this paper is derived from work commissioned by Affinity, the work undertaken is wholly independent of Affinity Water and should in no way be deemed to be reflective of Affinity Water or the those individuals thanked.

\section{COMPETING INTERESTS}

Authors have declared that no competing interests exist.

\section{REFERENCES}

1. United Nations Development Programme. Beyond scarcity: Power, poverty and the global water crisis. Palgrave Macmillan: New York; 2006.

2. United Nations Educational, Scientific and Cultural Organization. Water in a Changing World. Earthscan: London; 2009.

3. Doron U, Teh T, Haklay M, Bell S. Public engagement with water conservation in London. Water and Environment Journal. $2011 ; 25: 555-562$.

4. Department for the Environment Food and Rural Affairs. Water for Life. Defra: London; 2011.

5. Randolph B, Troy P. Attitudes to conservation and water consumption. Environmental Science and Policy. 2008; 11(5):441-455.

6. Chambouleyron A. Optimal water metering and pricing. Water Resources Management. 2004;18:305-319.

7. European Commission. The water framework directive: Tap into it! EC: Brussels; 2002.

8. Department for the Environment Food and Rural Affairs. United Kingdom Climate Change Risk Assessment. Defra: London; 2012.

9. National Metering Trials Working Group. National Metering Trials Final Report. Water Services Association: London; 1993.

10. Hamilton LC. Saving water: A causal model of household conservation. Sociological Perspectives. 1983;26(4): 355-374.

11. Baldassare $M$, Katz $C$. The personal threat of environmental problems as predictor of environmental practices. Environment and Behaviour. 1992;24(5):602-616.

12. Sadalla EK, Krull JL. Self-presentational barriers to resource conservation. Environment and Behaviour. 1995;27(3): 328-353.

13. De Young R. Some psychological aspects of reduced consumption behaviour: The role of intrinsic satisfaction and competence motivation. Environment and Behaviour. 1996;28(3):358-409. 
14. De Oliver M. Attitudes and inaction: A case study of the manifest demographics of urban water conservation. Environment and Behaviour. 1999;31(3):372-394.

15. Lam SP. Predicting intentions to conserve water from the theory of planned behaviour, perceived moral obligation, and perceived water right. Journal of Applied Psychology. 1999;29(5):1058-1071.

16. Stern PC. Information, incentives, and proenvironmental customer behaviour. Journal of Customer Policy. 1999;22(4): 461-478.

17. Gilg A, Barr S. Behavioural attitudes toward water saving? Evidence from a study of environmental actions. Ecological Economics. 2006;57(3):400-414.

18. Barr S. Factors influencing environmental attitudes and behaviours. Environment and Behaviour. 2007;39(4):435-473.

19. Gregory GD, Di Leo M. Repeated behaviour and environmental psychology: The role of personal involvement and habit formation in explaining water consumption. Journal of Applied Social Psychology. 2003;33(6):1261-1296.

20. Fujii S. Environmental concern, attitude toward frugality, and ease of behaviour as determinants of pro-environmental behaviour intentions. Journal of Environmental Psychology. 2006;26(4): 262-268.

21. Steg L, Vlek C. Encouraging proenvironmental behaviour: An integrative review and research agenda. Journal of Environmental Psychology. 2009;29(3): 309-317.

22. Robson C. Real-world research: A resource for social scientists and practitioner researchers. ( $2^{\text {nd }}$ ed.). Oxford, U.K: Blackwell; 2002.

23. Patton M. Qualitative evaluation and research methods. London, U.K: Sage. Prosser, I. (2011). Water: Science and solutions for Australia. CSIRO: Australia; 2002.

24. Denzin N. The research act in sociology: A theoretical introduction to sociological methods. London: Butterworths; 1989.

25. Hancock B. Trent focus for research and development in primary health care: An introduction to qualitative research. Trent Focus; 2002.

26. Hoggart K, Lees L, Davies A. Researching human geography. London: Arnold; 2002.

27. Kollmuss A, Agyeman J. Mind the gap: Why do people act environmentally and what are the barriers to pro-environmental behaviour? Environmental Education Research. 2002;8(3):239-260.

28. Blake J. Overcoming the 'value-action gap' in environmental policy: Tensions between national policy and local experience. Local Environment. 1999;4(3):257-278.

29. Jorgensen B, Graymore M, O'Toole K. Household water use behaviour: an integrated model. Journal of Environmental Management. 2009;91(1):227-236.

(C) 2016 Jenkins et al.; This is an Open Access article distributed under the terms of the Creative Commons Attribution License (http://creativecommons.org/licenses/by/4.0), which permits unrestricted use, distribution, and reproduction in any medium, provided the original work is properly cited. 